\title{
Calendarios indígenas y santoral católico
}

\section{Resumen}

\section{$\triangle$}

La beligerante resistencia indígena frente a la colonización en la actual Nicaragua está demostrada en numerosos eventos vinculados con su vida económica, política y religiosa. Durante el proceso de imposición del cristianismo, los frailes utilizaron métodos radicales para erradicarles sus creencias y cosmovisión. Ante esas intenciones nuestros ancestros recurrieron a numerosas maniobras para encubrir, proteger y preservar a sus dioses, entre ellas, acudir a sus templos para hacerles creer que adoraban al dios católico. Ejemplos de lo aseverado es la imagen del Sol (Quetzalcóatl), que aún está al centro de la nave principal de la iglesia de Sutiaba en León, o en los ritos a sus deidades que los indígenas aún realizan dentro del templo católico de Chichicastenango, en Guatemala.

En este breve ensayo se muestra la trasposición que hizo la Iglesia al imponer su santoral católico a las festividades indígenas.

Palabras clave: Colonización, resistencia, cosmovisión, calendario indígena, santoral católico.

Antes que de ultramar llegara la hecatombe, nuestros astrólogos seguían en los abismos del cielo los desplazamientos de las constelaciones, predecían eclipses y movimientos del Sol y la Luna, y cambios cíclicos de la naturaleza; sus agrónomos cultivaban alimentos en amplias extensiones; y sus ingenieros edificaron Teotihuacán, Chichén Itzá, Machu Picchu. Su sabiduría la perpetuaron en códices, estelas y calendarios, siendo constatada su innegable exactitud por investigadores con los instrumentos más avanzados de la tecnología contemporánea, aunque para numerosos aspectos de su civilización aún no han encontrado explicación científica.

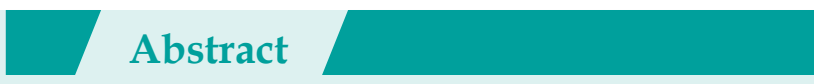

The belligerent indigenous resistance against colonization in the current Nicaragua is demonstrated in numerous events associated with their economic, political and religious life. During the process of the imposition of Christianity, the friars used radical methods for eradicate their beliefs and worldview.

Before these intentions our ancestors resorted to numerous maneuvers to cover up, protect and preserve their gods, among them, to go to their temples to make them believe that they worshiped the Catholic god. Examples of the asserted is the image of the Sun (Quetzalcoatl), which is still at the center of the main nave of the church of Sutiaba in Leon, or in the rites to their deities that the natives still celebrate in the Catholic temple of Chichicastenango, in Cuatemala.

In this brief essay shows the transposition made by the Church to impose its Catholic saints to the indigenous festivities.

Key words: Colonization, resistance, worldview, indigenous calendar, Catholic saints.

Con relación al Tiempo, los mayas iniciaban el nuevo año el 15 de enero, evento consagrado a Tezcatlipoca, el gran cuerpo que se mueve en el firmament -la Osa Mayor; Señor del Cielo y la Tierra, en la cultura náhuatl (mexicas y otros pueblos mesoamericanos), fuerte, omnipresente e invisible, fuente de vida, tutela y amparo del hombre, origen del poder, la felicidad, y dueño de las batallas. En Nicaragua, los pueblos maribio-sutiabas, dirianes, nahuas, sumos y matagalpas, lo iniciaban el 15 o 20 de enero, ofrendando al Sol guerreros enemigos que, en busca de bendiciones, inmolaban a flechazos. 


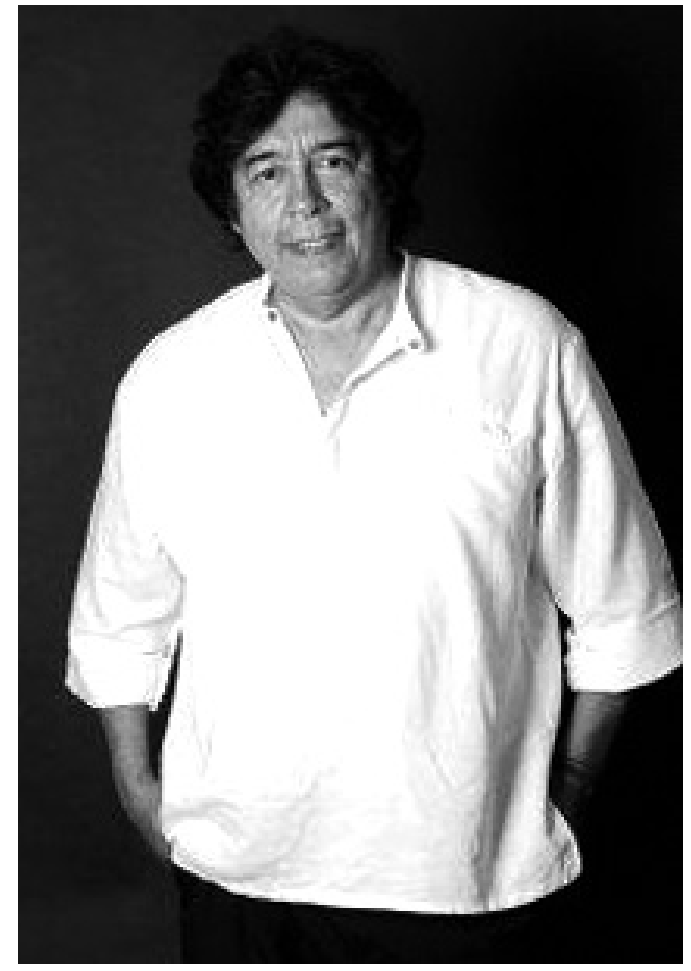

Mario Urtecho, escritor.

Nuestros ancestros evocaban los grandes acontecimientos de sus vidas con multitudinarios festejos, arrebatados por la Iglesia durante el proceso de dominación cultural de la colonización. Ante tal imposición, los pueblos originarios de América enmascararon sus creencias para preservarlas, haciéndoles creer a los intrusos que deponían a sus dioses y acogían a sus santos. Por ello, todas las fiestas patronales dirigidas por la Iglesia son permutas de las nativas, por lo que, como afirmó el Dr. Alejandro Dávila Bolaños, los calendarios indígenas aún tutelan las vidas de la mayoría del pueblo nicaragüense ${ }^{2}$.

Expresión de lo afirmado son las celebraciones el 15 de enero del Señor de Esquipulas en El Sauce y el 20 en Tipitapa, Esquipulas (Matagalpa), Carazo y Popoyuapa (Rivas), festividad también ofrecida a Nuestra Señora de los Desamparados y a Jesús Nazareno en San Fernando (Nueva Segovia), La Concepción, Santa Teresa, Nindirí, Totogalpa, Sébaco y otros lugares. Ocotal y Mozonte festejan al Señor de los Milagros; y Nandasmo al Señor la Buena Muerte y al Señor del Dulce Nombre.
Desde la lógica de la sustitución, el guerrero flechado de nuestros ancestros fue destituido por san Sebastián, mártir cristiano asaetado en Roma, y según la tradición diriambina hallado por pescadores en las aguas del mar en Huehuete mientras flotaba en un cajón de madera, donde también hallaron a Santiago, patrono de los jinotepinos. Desde entonces, el 20 de enero Guachán es festejado con bailes, máscaras, marimbas, vestimentas coloridas, comilonas y bebederas en Diriamba, Masaya, Granada, Darío, Boaco, Acoyapa, Juigalpa y San Sebastián de Yalí.

Otros pueblos indígenas, coincidiendo con los mexicanos, comenzaban el año nuevo el 2 de febrero, fecha importante, pues les señalaba que a partir de allí, en 90 días iniciaría el invierno, que según sus cálculos, comenzaba el 3 de mayo, día consagrado al dios de la Lluvia. Los indígenas representaban al dios de la Lluvia con una cruz. No es casual que esa fecha, el santoral católico celebre la Santa Cruz.

Los aborígenes de Nicaragua honraban a Xolotl, hermano gemelo de Coabol, la gran culebra, que en la cosmogonía nahua representaba al dios creador, que descendió al infierno -Migtán- en busca del Hueso del Muerto, del cual formó la primera pareja humana. Es la Luna, que tiene como nagual al Xulo, el dios con cabeza de perro, festividad indígena traspuesta por la de la virgen de Candelaria, cuyo templo estuvo a orillas del Xolotlán, donde antes del terremoto de 1931 también estuvo su iglesia, de festejos renombrados desde la colonia hasta inicios del siglo XX en Managua, Masaya, Carazo, Diriomo, El Viejo, Chichigalpa, Chontales, El Jícaro (Nueva Segovia), y La Trinidad (Estelí).

En otras partes celebraban el inicio del año el 3 de febrero -día de San Blas- igual que la gran fiesta de Cholula, México, dedicado a Quetzalcóatl, donde a medianoche ofrendaban a la Luna el corazón de un indio sano. En otros lados lo hacían el 8 de febrero, fecha que aún ofician encubierta con santa Clara de Luna y la virgen de Montserrat en La Concepción, Masaya; san Caralampio, en Cinco Pinos, Chinandega, y Diriamba. Incluso el 11 de febrero, con la virgen de Lourdes, en La Concordia, Jinotega; virgen de Los Remedios en Quezalguaque, y virgen del Chorro, en Telpaneca.

1 El arqueólogo Bayardo Gámez Montenegro recopiló ensayos del Dr. Alejandro Dávila Bolaños. Parte de ellos fueron publicados en Nicaragua prehispánica (octubre 1990), por el Centro de la Medicina Popular Tradicional de Estelí. 


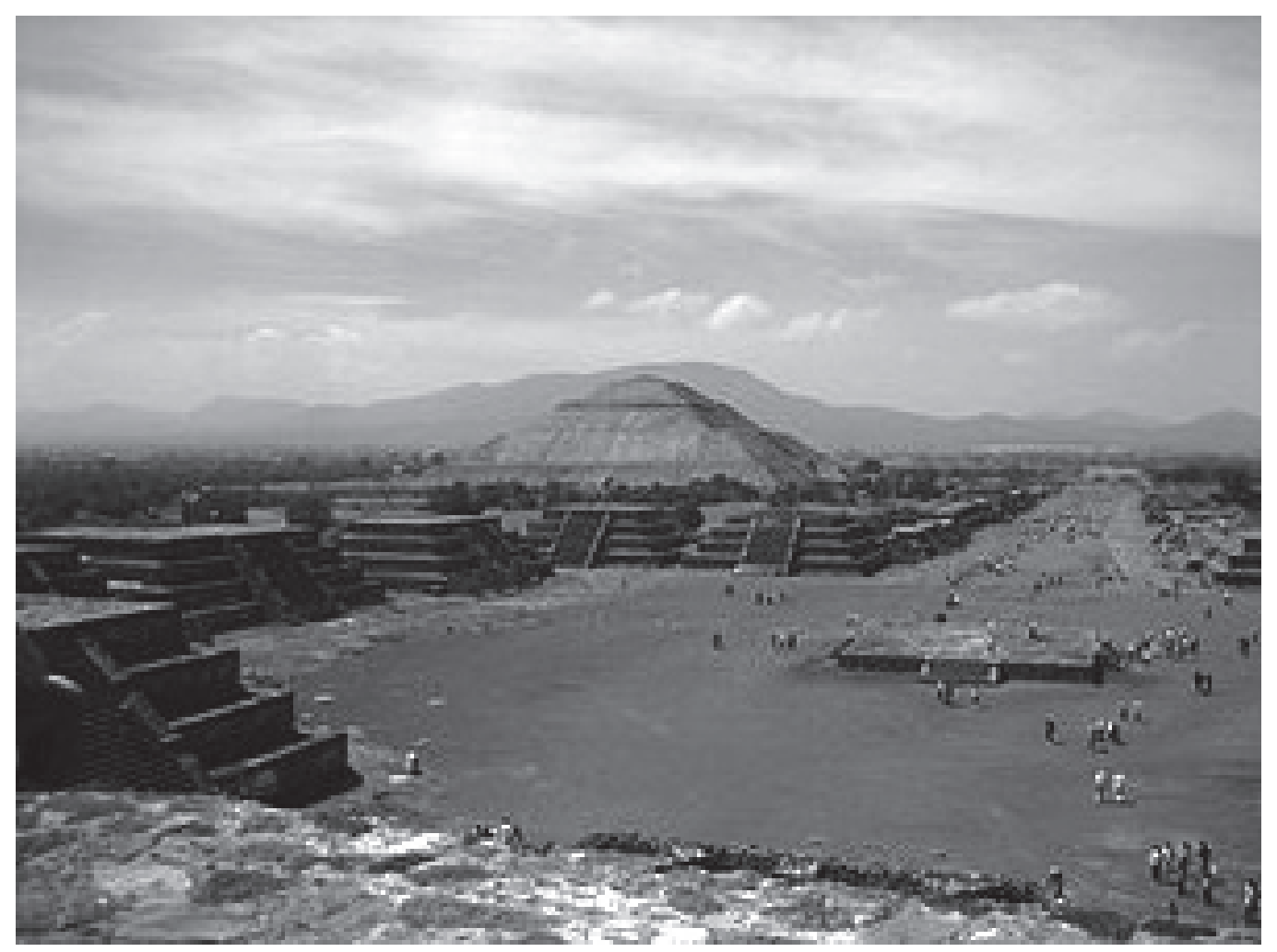

Teotihuacán (México), fue una de las mayores ciudades prehispánicas de Mesoamérica.

En la cosmovisión indígena, el ciclo solar anual, los cultivos y las festividades, estaban vinculados de manera especial. El ciclo solar anual comenzaba el 20 de enero, dos días después de haber finalizado 7 períodos de 52 días (364 días), medida de tiempo muy relacionada con las siembras, en especial la del maíz. El primer período terminaba el 12 de marzo, cuando debían haber concluido las tareas de socola (roza y destronque de bosques), en espera de la luna nueva, pasado el equinoccio de primavera, para iniciar la quema de los campos. Estas festividades fueron sustituidas por la Semana Santa y las de san Gregorio, nombre perpetuado en poblados y haciendas de Carazo, Masaya, Granada y Managua.

El invierno iniciaba el 25 de abril y concluía el 25 de octubre. Las fiestas del inicio de las lluvias fueron traspuestas con las de san Marcos, y prolongadas en Diriá hasta el 29, con las de san Pedro. Ese día, en Masaya bendecían semillas de maíz y frijoles, y cruces hechas de palmas de coyol, que protegían de no ser asados por los rayos. El segundo período señalaba el 3 de mayo, día exacto de la entrada de las lluvias, fecha extraordinaria para todos los pueblos antiguos de Nicaragua, que festejaban al dios de la Lluvia, generador de vida y comida, a quien pedían abundantes cosechas.

El tercer período marcaba el paso del sol, señalando su detención en el Norte, en el solsticio de verano, el 24 de junio, día de san Juan Bautista. Las festividades del 25 de julio eran dedicadas a Citaliclue, la Vía Láctea, cuando llegaba al cenit en las primeras horas de la noche. En esa fecha, o cerca de ella, la Iglesia celebra a la virgen del Carmen (15 de julio), y María Magdalena (20 de julio). La fiesta indígena del 25 de julio, dedicada a la Vía Láctea, fue traspuesta por la de Santiago, celebrándose aún en Jinotepe, Masaya, Granada, Managua, León, Boaco, Somoto, entre otros.

La cuarta vuelta, iniciada el 15 de agosto, fijaba el cierre del primer período de lluvias y la gran fiesta por el éxito de la tapisca del maíz. Xolotl, dios con cabeza de perro, dios Maíz, era la deidad central de los pescadores de la Managua precolombina, y tenía su templo en las sierras, donde sembraban maíz. En esta festividad era 


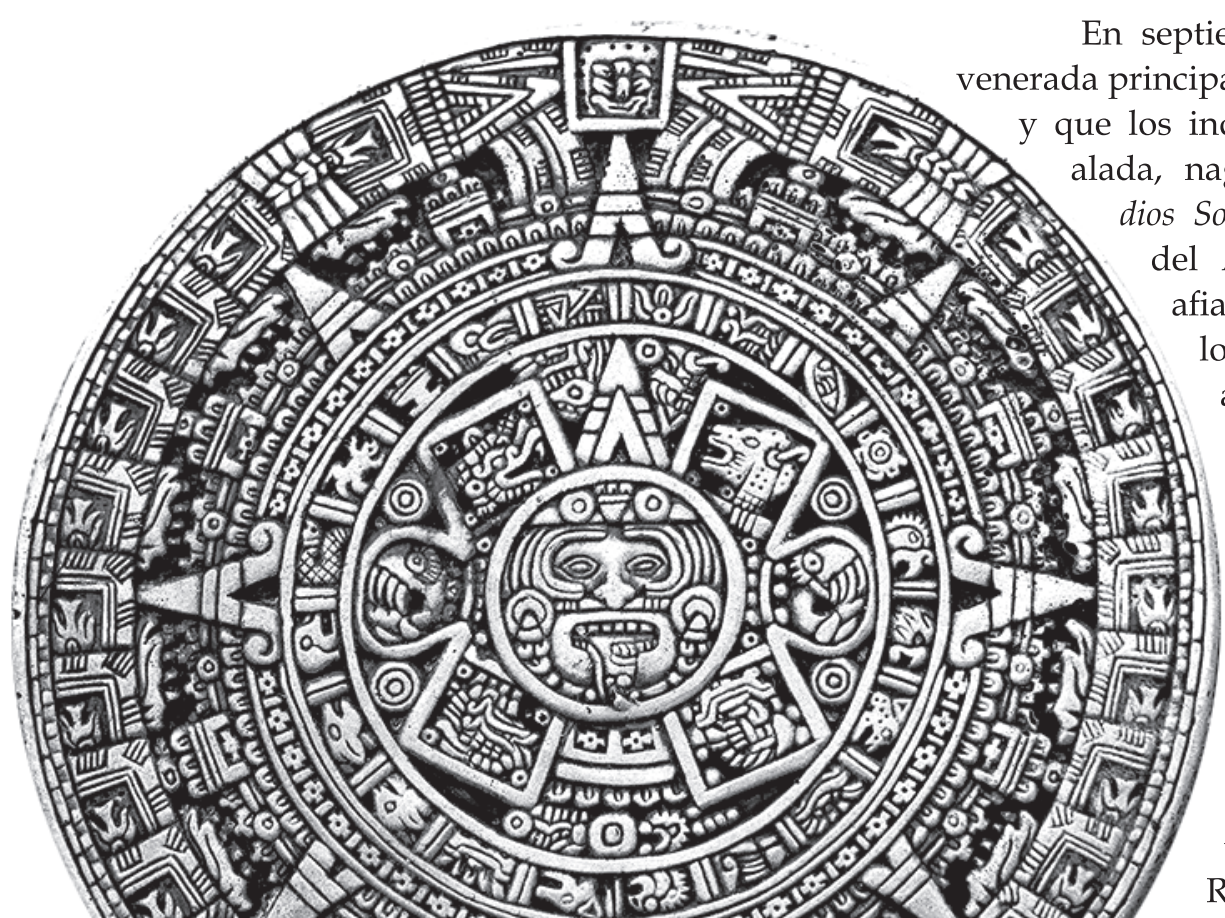

En septiembre, la imagen de san Miguel fue ipalmente por el dragón negro a sus pies, que los indígenas identificaron con la serpiente dios Sol, contribuyendo la espada flamígera del Arcángel, símbolo del rayo solar, a afianzar la devoción por la imagen. Para los chorotegas dirianes, el león que acompaña a san Jerónimo, era el nagual del volcán Masaya, el dios Fuego, una de sus grandes divinidades, a la que sacrificaban niños, jóvenes y mujeres, pidiéndole agua, buenas cosechas y victorias en las guerras.

La quinta rueda correspondía al 6 de octubre, fin de las siembras de maíz y frijoles de postrera, fiesta traspuesta por la de la virgen de El Rosario, vigente en el norte. El 25 de octubre concluía el invierno, con gran júbilo popular por el éxito de las cosechas y el descanso físico que representaba. Entre sus numerosas ceremonias estaba el destape del aire, su liberación, que hacían abriendo en sus templos los tecomates (calabazas), donde lo habían encerrado para que no causara desastres en los sembríos de maíz y frijoles. Así explicaban el "viento fresco" (dios

El Calendario Maya tenía tres diferentes y simultáneas cuentas de tiempo: el Sagrado o Tzolkin de 260 días, el Civil o Haab, de 365 días o kim, y la Cuenta Larga, de 144.000 días, es decir 20 ciclos de 20 años.

"bajado" y paseado en una canoa (acali), en las aguas del lago Xolotlán, consagrado a él. Esta es la razón de la presencia del barco, donde depositan la imagen de santo Domingo -vale decir del perro, nagual de Xolotl-, para que ingrese a la ciudad.

Los chorotegas (Masaya, Granada y Carazo), celebraban fiestas el 15 de agosto, agradeciendo a sus dioses y diosas por el éxito de las siembras. Fueron sustituidas por las de la virgen de La Asunción, también festejada en Palacagüina, Juigalpa, y otras localidades. La parroquia de La Asunción, en Masaya, tiene en la parte superior de su frontispicio, la imagen de busto de la virgen María, con una culebra cascabel a sus pies, nagual del Sol, y principal deidad acuática de los indios diriegas.
Hecat), característico de la última semana de octubre, identificado por sus alas con el Arcángel san Rafael (llamado el Sembrador en Pueblo Nuevo, Estelí), muy vinculado con el nagual del maíz, por el pescado que tiene en su mano.

La sexta vuelta terminaba el 27 de noviembre, inicio de las grandes festividades del cierre del año agrícola, que terminaba entre el 8 y el 9 de diciembre con solemnes ceremonias. No es casual que el 8 de diciembre sea celebrada en toda Nicaragua, la purísima Concepción de María, precedida el día 7, con multitudinarias griterías en su honor. El 9 de diciembre aún es celebrado en la antigua Namotiva (hoy Catarina), con la fiesta en honor a santa Catalina. Este ciclo solar terminaba el 18 de enero, confundiéndose con las festividades rituales del comienzo del año nuevo indígena.

Todo esto parece ratificar que los calendarios indígenas aún tutelan las vidas del pueblo nicaragüense. 